\title{
STRUCTURE OF SCABIOSIDE G
}

\author{
V. G. Bukharov and V. V. Karlin
}

Khimiya Prirodnykh Soedinenii, Vol. 6, No. 3, pp. 373-374, 1970

UDC $547.597+547.918$

Scabioside G, the most polar glycoside of Patrinia scabiosofolia Fisch. et Link, has $\operatorname{mp} 235-236^{\circ} \mathrm{C}[\alpha]_{\mathrm{D}}^{20}-7^{\circ}$ (c 5.7, pyridine) [1]. Its molecular weight corresponds to that of a hexaoside of oleanolic acid. When scabioside $G$ was heated with mineral acids, the hydrolysate was found by paper chromatography to contain the same monosaccharides as the pentaoside scabioside F: D-glucose, D-xylose, L-arabinose, and L-rhamnose [2]. Like scabiosides D, E [1], and F, on saponification on an anion-exchange resin the glycoside is converted into scabioside $\mathrm{B}$ [3]. On being heated with acid, the permethyl ether of scabioside G formed 2,3,4,6-tetra-O-methyl-Dglucopyranose, 2, 3-di-O-methyl-L-arabinopyranose, 2, 3-di-O-methyl-L-xylopyranose, and 2,4-di-O-methyl-Lrhamnopyranose.

In the reductive cleavage of the permethylate with lithium aluminum hydride and subsequent hydrolysis of the reduced methylated tetrasaccharide, in addition to the methylated monosaccharides mentioned above 2,3-di-Omethyl-D-xylitol was formed. Thus, in the tetrasaccharide chain of the glycoside one xylopyranose is attached directly to the carboxyl of the aglycone and glucopyranose is found at the end of a straight unbranched chain.

Furthermore, by alkaline saponification on an anion-exchange resin, scabioside G yielded a tetrasaccharide which was reduced with sodium borohydride and subjected to partial acid hydrolysis. By preparative paper chromatography, an unreduced disaccharide which decomposed on hydrolysis into rhamnose and xylitol was isolated from the mixture of products.

These facts, and also the results of methylation, show the presence in the tetrasaccharide of the fragment L-rhamnopyranose-( $1 \rightarrow 4)$-D-xylopyranose. It is clear from this that the sequence and nature of the links of the monosaccharide members in the carbohydrate chain attached to the carboxyl in scabioside G coincides with those of scabioside F. This circumstance and the genetic linkage between the scabiosides shown previously [2] permits the assumption that scabioside $\mathrm{G}$ is the terminal product of synthesis in the plant. Conseguently, the configuration of all the analogous glycoside centers in scabiosides $\mathrm{F}$ and $\mathrm{G}$ may be regarded as identical, which makes it possible to determine the configuration of the glycoside center of the terminal glucopyranose ( $\alpha$-linkage) from the difference in the molecular rotations between scabiosides $\mathrm{F}$ and $\mathrm{G}$.

On the basis of all the facts considered above, the structural formula of scabioside $G$ is as follows

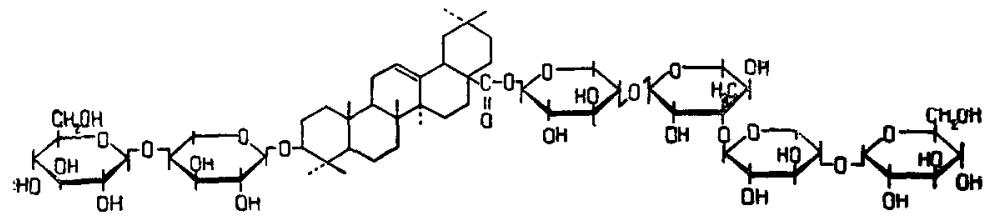

\section{R E F ERENCES}

1. V. G. Bukharov and V. V. Karlin, KhPS [Chemistry of Natural Compounds], 6, 211, 1970.

2. V. G. Bukharov and V. V. Karlin, KhPS [Chemistry of Natural Compounds], 6, 372, 1970 [in this issue].

3. V. G. Bukharov, V. V. Karlin, and T. N. Sidorovich, KhPS [Chemistry of Natural Compounds], 6, 69, 1970.

21 October 1969

Arbuzov Institute of Organic and Physical Chemistry, AS USSR 